\title{
Spatio-temporal evaluation of cattle trade in Sweden: description of a grid network visualization technique
}

\author{
Stefan Widgren ${ }^{1}$ Jenny Frössling ${ }^{1,2}$ \\ ${ }^{1}$ Department of Disease Control and Epidemiology, National Veterinary Institute, Uppsala, Sweden; \\ ${ }^{2}$ Department of Animal Environment and Health, Swedish University of Agricultural Sciences, Skara, Sweden
}

\begin{abstract}
Understanding the intensity and spatial patterns of animal transfers is of prime importance as geographical moves play an important part in the spread and potential control of contagious animal diseases of veterinary importance. For the purpose of visualizing all registered between-herd animal movements in Sweden between 1 July 2005 and 31 December 2008 by map animation, a grid network technique based on the Bresenham line algorithm was developed. Potential spatio-temporal clustering of animals registered as sold or purchased based on location and month of trade was also detected and tested using a spatial scan statistic. Calculations were based on data from 31,375 holdings and 3,487,426 head of cattle. In total, 988,167 between-herd movements of individual bovines were displayed in a sequence of maps covering three and a half years by 2 -week intervals. The maps showed that several cattle movements, both short- and long-distance, take place in Sweden each week of the year. However, most animals $(75 \%)$ were only registered at one single holding during the study period and $23 \%$ were sold to a different holding once. Spatial scan statistics based on data from the year 2008 indicated uneven distributions of purchased or sold animals in space and time. During each autumn, there was an increase in cattle movements and October and November showed significantly more cases of sold or purchased animals (relative risk $\sim 1.7, p=0.001$ ). Based on the results, we conclude that cattle trade is constantly active at a considerable level. This, in combination with possibly insufficient biosecurity routines applied on many farms, constitutes a risk that contagious diseases are spread in the population. The grid network maps were generated through the use of open-source tools and software in order to decrease software costs and facilitate sharing of programme code. In addition, the technique was based on scripts that allow for the inclusion of iterative processes and that comprise all main parts of map creation. Thereby, a large number of maps can be generated and the demands for high reproducibility are met.
\end{abstract}

Keywords: Bresenham line algorithm, open-source, map animation, cluster analysis, Sweden.

\section{Introduction}

For many contagious diseases in production animals, transfer between herds is considered the most important cause for spread of disease. Major restrictions of movements in zones or regions can temporarily be used to control disease outbreaks and restrictions of trade between herds with different

Corresponding author:

Stefan Widgren

Department of Disease Control and Epidemiology

National Veterinary Institute

SE-751 89 Uppsala, Sweden

Tel. +4618 674000; Fax +4618674445

E-mail: stefan.widgren@sva.se disease status can also be applied continuously in disease control programmes. This is generally put into operation in Europe during outbreaks of exotic and emerging diseases such as foot-and-mouth disease and bluetongue (BT) (Anonymous, 2003, 2007), as well as in the control of endemic diseases such as bovine viral diarrhoea (Lindberg and Alenius, 1999). Because movements of animals can be expected to play an important part in the spread and means for control of diseases, it is important to understand the intensity and spatial pattern of movements.

Until recently, background information or analysis on animal movements in Sweden for surveillance or research purposes have been lacking and pre- 
dominantly based on expert opinion. Currently, however, reporting of all movements of individual bovines between holdings is mandatory (Anonymous, 2009a). Since 1998, all cattle are tagged with their unique identity number, which is recorded in a national register. This is based on the European Union regulation regarding identification of cattle (Anonymous, 2000), which in part was initiated due to the bovine spongiform encephalopathy outbreak in the 1990s. Since then, studies on animal movements in European countries are facilitated and results have been reported, e.g. from Denmark, Portugal and United Kingdom (Bigras-Poulin et al., 2006; Robinson and Christley, 2006; Matos Baptista and Nunes, 2007). Recently, the first studies on livestock movements in Sweden were also presented (Nöremark et al., 2009a).

The application of geographical information systems (GIS) and maps for visualisation purposes is a powerful approach as it enables an overview of rather complex patterns in space and time. Both the software and maps needed to perform exploratory, spatio-temporal analyses are often expensive. However, as the knowledge and general use of GIS has increased and more license options have been developed, several open-source alternatives have become available, e.g. through the Open Source Geospatial Foundation (http://www.osgeo.org). Another prerequisite for this kind of exploratory analysis is presence of geo-referenced data. For animal holdings in Sweden the information on specific location is still incomplete but the national register of such data is continuously improving.

The aim of this study was to investigate patterns of cattle trade in Sweden by visualisation and animation of registered between-herd animal movements. One reason for examining the specific data used was to explore and prepare a dataset for further simulation studies on disease spread in the Swedish cattle population. In order to facilitate updating of results and sharing of technique, we further aimed at including all parts of the visualisation process in one complete programme code to be applied using open-source software.

\section{Materials and methods}

This paper describes a technique that can be utilised for repeated visualisation of movements such as movement of cattle between holdings. The basis for the method is to draw lines between source and destination holdings for each reported animal. By summarising the number of animals passing through areas, the transfer intensity can be shown by using different colours of the connecting lines. In this study, the described technique was applied on all reported, between-herd cattle movements generating a sequence of maps covering three and a half years by 2 -week intervals.

\section{Study population}

The study comprised all Swedish cattle herds including holdings with as little as one individual bovine at some point in time during the study period that spanned the period of 1 July 2005 to 31 December 2008. Information about animal identities (including individual number and date of birth), movement of cattle and location of animals and herds, was based on data retrieved in 2009, from the Swedish Board of Agriculture, where the national animal-movement and holding location registries are kept. All records for animal identities where multiple birthdates were registered (1,300 identities) were removed from the dataset. Overall, the data comprised 31,375 holdings and 3,487,426 individual bovines.

In the data retrieved from the Swedish Board of Agriculture, the exact locations of holdings were given as specific coordinates for 27,248 (87\%) of them. The coordinates originated from different sources, e.g. different registers of land use or animal holdings. For holdings where coordinates were missing, the location was approximated by applying centre coordinates of the 3-digit postal code area for each holding. Centre coordinates were identified based on a digitized map of Sweden (Sverige 1000plus, version 5/2004, Statistics Sweden). The distribution and relative size of postal code areas are 
presented in Fig. 1. Both original coordinates and information on postal codes areas were missing for 49 of the holdings $(0.2 \%)$, which were subsequently excluded from the spatial analysis.

The geographical distribution of the background population is presented in Fig.1. Herds are predominantly located in the southern part of the country and along the northern part of the Baltic coast. In 2008 , by the end of the study period, there were approximately 22,800 agricultural cattle enterprises in Sweden according to official statistics (Anonymous, 2009b). Approximately 6,500 of the herds were registered as delivering milk, i.e. dairy herds. Other herds were either suckler herds (herds

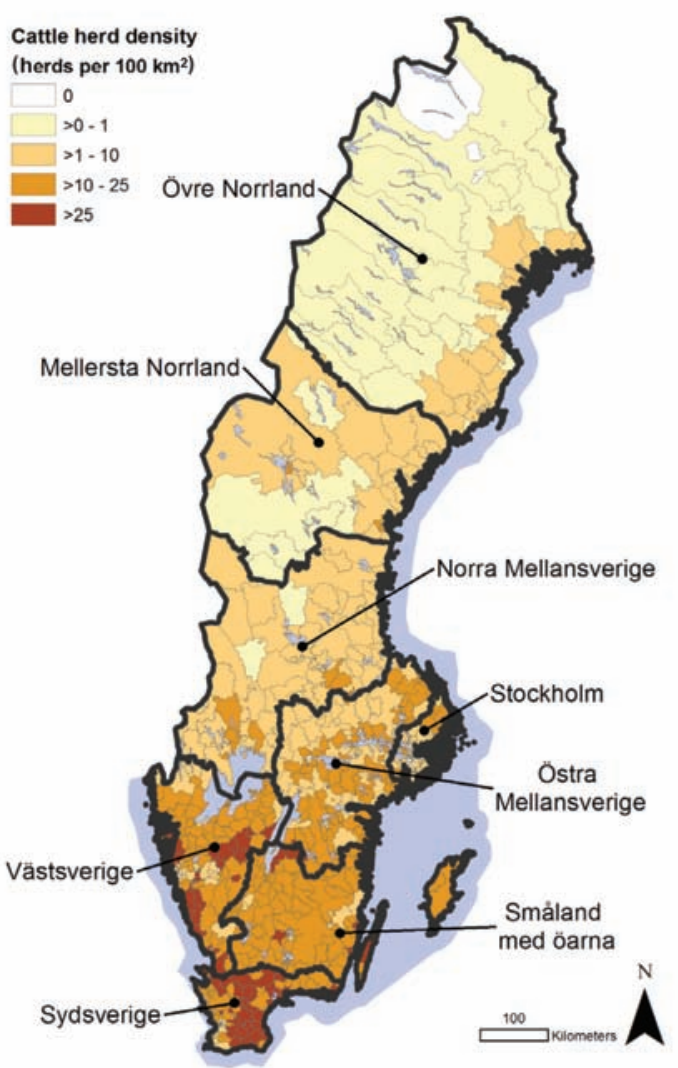

Fig. 1. Density of cattle herds (herds per $100 \mathrm{~km}^{2}$ ) by postal code area in Sweden in 2009. (C) Lantmäteriet Gävle 2009, permission number I 2009/0830. The map also includes borders of the 8 regions corresponding to European Union NUTS (level 2). with animals of beef breeds where animals are raised for breeding purposes and/or for beef production) or herds with young stock (mostly of dairy breed) for meat production.

\section{Transfer between holdings}

Data on animal movements between holdings were based on purchase and sale reports. Each report in the database contains information about the source and destination holding, the animal identification, the birth date of the animal and the report date. Every purchase or sale of individual bovines is supposed to be reported by both the seller and buyer. In theory, two identical reports should therefore exist for each transfer between two holdings. However, this is not always the case, even though reporting is mandatory. In this study, movements were not only based on matched sale and purchase reports, but also on some single reports. Evaluation of reports and decision about inclusion of movements in the final dataset was performed in a series of passes as follows.

First, the reports for each animal identity were matched according to source holding, destination holding and date of movement. In case information on holdings differed in the purchase report in comparison with the sale report, the source holding of the movement was always set to the holding that reported the sale and the destination holding was set to the holding that reported the purchase. For between-herd transfers with non-matching dates of movement in the respective reports but matching animal identity, the date used was the date halfway between the two dates reported. In case both information on holdings and date of movement did not match, the movement was accepted if the dates differed with no more than seven days. At this stage, all remaining unmatched reports for an individual animal were kept in the dataset.

After this, between-herd movements were checked against the registered birth date of the animal and the reported dates for slaughter or euthanization. Transfers outside the lifespan of individual animals 
were excluded from the dataset. Finally, all remaining movements for each animal were sorted in time and duplicated movements to the same destination were excluded together with movements from single matched reports where the source holding were inconsistent with the current location of the animal.

\section{Grid network visualization of animal movements between holdings}

To investigate the spatial and temporal pattern of the movement of animals between holdings a grid network technique was developed. The aim was to visualise both the regional intensity and the spatiotemporal distribution of the animal movements between holdings. To achieve this, the georeferenced holdings, using the Swedish national projection (RT 902.5 gon $\mathrm{V}$ 0:-15), were projected onto a grid with squre cells with side $L$. In this presentation, the cell side $L$ equals $1,000 \mathrm{~m}$. The index $(i, j)$ to the cell that contained the holding with coordinate $(x, y)$ was calculated using integer floor division with the grid cell size $L$ after subtracting the (left, top) coordinate of the grid.

$$
(i, j)=\left(\left[\frac{y-t o p}{L}\right]+1,\left[\frac{x-l e f t}{L}\right]+1\right)
$$

The sequence of $(i, j)$ pairs for a movement of an animal from the source holding $(i, j)_{\text {source }}$ to the destination holding $(i, j)_{\text {destination }}$ were determined by the Bresenham line algorithm (Bresenham, 1965). This algorithm determines which cells in an $m \times n$ dimensional grid that the movement passes through in order to form a close approximation to a straight line between the source and destination holding. It needs to be kept in mind that this approximation by no means corresponds to the actual route of the animal transport.

To include the temporal information of the movements, the dates of the movements were converted from date format to integer days where day 0 equals min(date) of all movements to visualise, and subsequent days were conted from day 0 and given as 1 , 2 , etc. Movements were then grouped by setting a time resolution $T$ in days, so that each movement received an index $t$ that was calculated by integer floor division. In this paper, the time resolution $T$ was set to 14 days:

$$
t=\left[\frac{d a y}{T}\right]+1
$$

To count the number of passages through each cell in the grid a $m \times n$ dimensional counter matrix $C_{t}$ were defined for each

$$
t=1,2, \ldots,\left[\frac{\max (\text { day })}{T}\right]
$$

where each $c_{i j}$ holds the number of animals that had passed through the cell with index $(i, j)$ during its passage from the source to the destination holding at time index $t$. In this material max(day) equals 1,280 .

$$
C_{t}=\left[\begin{array}{cccccc}
C_{11} & C_{12} & \cdots & C_{1 j} & \cdots & C_{1 n} \\
C_{21} & C_{22} & & & & C_{2 n} \\
\vdots & & \ddots & & & \vdots \\
C_{i 1} & & & \ddots & & C_{i n} \\
\vdots & & & & \ddots & \vdots \\
C_{m 1} & C_{m 2} & \cdots & C_{m j} & \cdots & C_{n n}
\end{array}\right]
$$

For each cell $(i, j)$ that a movement passes through during its way from the source holding to the destination holding at time index $t$, the counter $c_{i j}$ in $C_{t}$ is incremented by 1 . Before the movements are counted, the counter $C_{t}$ for all $t$ is initialized to zero.

$$
C_{t}=\left[\begin{array}{ccc}
0 & \cdots & 0 \\
\vdots & \ddots & \vdots \\
0 & \cdots & 0
\end{array}\right]
$$

The number of passages through each cell was counted by an iterative process over all movements for all days. The described method was implemented in Python 2.5 (Lutz, 2007). The resulting counter matrices $C_{t}$ were saved as georeferenced raster files in the ArcInfo ASCII Grid format (ESRI; Redlands, CA, USA). The ArcInfo ASCII Grid head- 
er was set to the following: ncols and nrows equals the size of the counter matrix, xllcorner and yllcorner are calculated from the (left, top) coordinate, nodata_value equals zero and the cellsize equals the grid size $L$.

Post-processing of the raster files were done using GRASS GIS 6.4 (GRASS Development Team 2009. Geographic Resources Analysis Support System, GNU General Public License. http://grass.osgeo. org). To be able to compare the different time periods, the same colour table was used for each raster, where $\max \left(c_{i j}\right)$ for all $t$ determines the rules used for the scale of the colour table (Neteler and Mitasova, 2008). To view the animal movements between holdings as an animation, all maps were exported as Portable Network Graphics (PNG) and subsequently converted to an animation with ImageMagick (ImageMagick Studio LLC, Landenberg, PA, USA).

\section{Example of how the Bresenham line algorithm} can be applied on animal movements between two holdings

Assume that there is (i) a movement of one animal at day 9 from a holding located in cell $(2,2)$ to a holding in cell $(6,10)$ (as in Fig. 2), and (ii) a move-

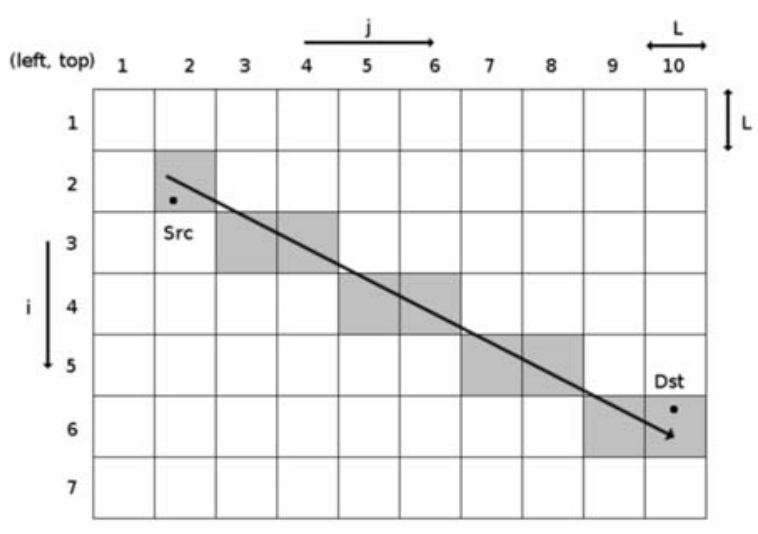

Fig. 2. Example grid with 7 rows $(i)$ and 10 columns $(j)$ showing the result of applying the Bresenham line algorithm in the illustration of a movement of one animal between a source (Src) holding and a destination (Dst) holding, where $L$ is the grid cell size. ment of one animal at day 13 from a holding located in cell $(6,6)$ to a holding in cell $(3,9)$.

Then the Bresenham line algorithm yields the following set of cells:

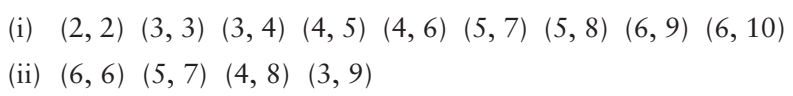

If the time resolution $T$ is set equal to 14 days, then $t=1$ for both movements and the resulting counter matrix equals

$$
C_{t}=\left[\begin{array}{llllllllll}
0 & 0 & 0 & 0 & 0 & 0 & 0 & 0 & 0 & 0 \\
0 & 1 & 0 & 0 & 0 & 0 & 0 & 0 & 0 & 0 \\
0 & 0 & 1 & 1 & 0 & 0 & 0 & 0 & 1 & 0 \\
0 & 0 & 0 & 0 & 1 & 1 & 0 & 1 & 0 & 0 \\
0 & 0 & 0 & 0 & 0 & 0 & 2 & 1 & 0 & 0 \\
0 & 0 & 0 & 0 & 0 & 1 & 0 & 0 & 1 & 1 \\
0 & 0 & 0 & 0 & 0 & 0 & 0 & 0 & 0 & 0
\end{array}\right]
$$

\section{Testing of spatial and temporal clustering}

In order to investigate potential geographical and seasonal differences in the proportion of sold or purchased animals in relation to the total number of animals in herds, numbers were summarized for each postal code area and month based on records from 2008. Clustering of animals registered as sold or purchased based on location and month of movement was then detected and tested using the spatial scan statistic (Kulldorff and Information Management Services, Inc. SaTScan ${ }^{\mathrm{TM}}$ version 7.0, 2006; www.satscan.org). The testing was performed using a Bernoulli model (Kulldorff, 1997) where the traded animals were considered cases and non-traded animals considered controls. This scan statistic is based on input by point data, and locations of cases and controls were therefore given as centre coordinates of postal code areas. The reason for summarising data by postal code area was to decrease the total number of locations and thereby be able to meet software demands for computer memory. The maximum cluster size in space and time was set to $25 \%$ of the pop- 
ulation at risk and $25 \%$ of the study period (2008), respectively. Both circular and elliptic cluster shapes were applied. Significance of clusters was tested using Monte Carlo hypothesis testing (999 permutations). Population densities and results from the spatial scan statistic were visualised in maps created in ArcView version 9.2 (ESRI; Redlands, CA, USA).

\section{Results}

The material collected included 972,067 reported events from buyers and 983,329 from sellers. The result of matching of reported purchase and sale events are summarised in Table 1. In total, 988,167 movements remained after the evaluation of reports and were included in the study. For $76 \%$ of the reported events there was a perfect match. The most frequent reason for records not being perfectly matched was differences in the reported date of the sale and the purchase event. Another frequent reason was that the seller, say $X$, reported that the animal was sold to holding $Y$, while the buyer $(Y)$ erroneously reported holding $Z$ as the seller. The reason that there are more matched movements than reported sale or purchase events, respectively, is the existence of reports that are only reported either by the seller or the buyer, and these events were included as a transfer.

Table 1. Number and type of movement events, registered in the Swedish Board of Agriculture database on movements of individual cattle, and included in the study (1 July 2005 - 31 December 2008).

\begin{tabular}{lr}
\hline Description & \multicolumn{1}{c}{$\mathrm{N}$} \\
\hline Reported purchase events & 972,067 \\
Reported sell events & 983,329 \\
& \\
Movements with perfect match & 752,328 \\
Movements with non-matching holdings & 69,181 \\
Movements with non-matching dates & 126,675 \\
Movements with non-matching holdings and dates & 4,255 \\
Movements from single reports & 35,728 \\
& \\
Excluded movements & 12,151 \\
& \\
Total number of movements included & 998,167 \\
\hline
\end{tabular}

According to the data, most traded animals were young with a median age of 156 days when moved. There were three distinct peaks in the age of the traded animals (Fig. 3), i.e. around 80, 220 and 750 days of age. The median number of movements between holdings for each individual animal was 0 (range: $0-8)$. Most animals $(\mathrm{n}=2,602,246 ; 75 \%$ ), were only registered at one single holding during the study period, while $23 \%$ of the animals registered one transfer event.

On average, there were 5,413 animal movements per week but the transfers were not evenly distributed over the year but ranged from 2,438 movements in December 2008 to 10,395 movements in October 2008. This marked, seasonal pattern seemed to be replicated throughout the study period (Fig. 4). During each autumn from 2005-2008, there was a striking increase in cattle movements which peaked by the end of October followed by a rapid decline by the end of the year. In the spring and early summer, a second peak of transfer was noted.

The numbers of sold and purchased animals, within and between different parts of Sweden during 2008 are summarised in Table 2, where the frequencies are aggregated according to the European Union Nomenclature of Territorial Units for Statistics (NUTS), level 2. The regions correspon-

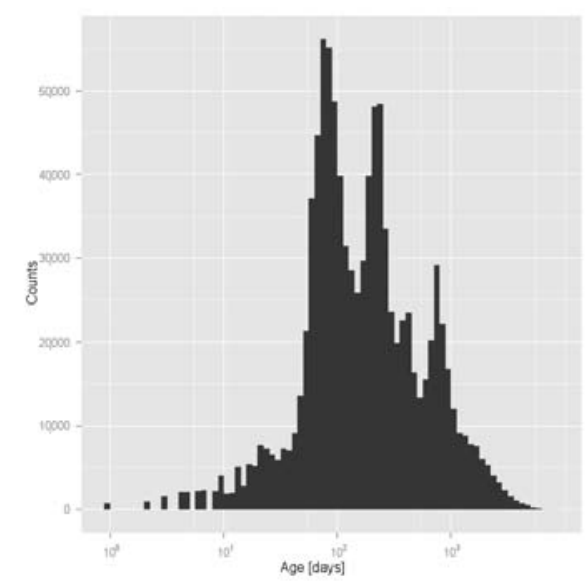

Fig. 3. Age (in days) of individual bovines at the day of movement between two different holdings as registered in the database of the Swedish Board of Agriculture and included in the study (1 July 2005 - 31 December 2008). 


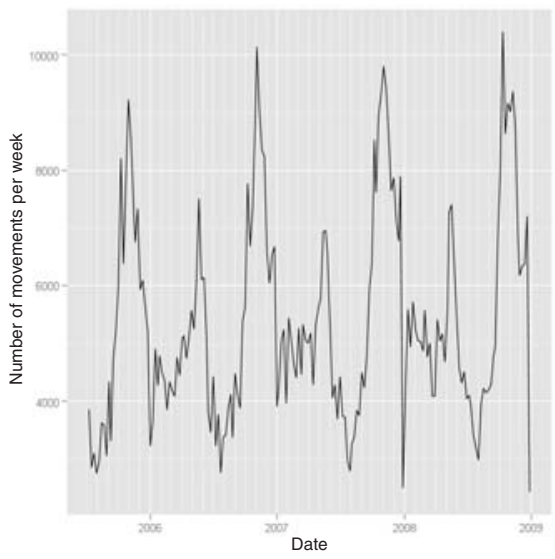

Fig. 4. Number of registered movements of individual cattle between two different holdings per week during the study period (1 July 2005 - 31 December 2008). ding to NUTS codes, level 2 in Sweden are mapped in Fig. 2. The crude proportions of sold or purchased animals in different regions during this year were similar (approximately $12-14 \%$ and $8-15 \%$, respectively). However, the proportion of animals sold to or purchased from other regions varied considerably. Many regions with a relatively large proportion of animals purchased from other regions also had a large proportion of animals sold to other regions. One exception was middle region of the northern part of the country ("Mellersta Norrland"), which had a much larger proportion of sold animals to other regions $(34.9 \%)$ compared to purchased animals from other regions $(9.9 \%)$.

Examples of map illustrations of the movements

Table 2. Frequencies and proportions of individual cattle sold and purchased within and between different regions, i.e. European Union NUTS (Nomenclature of Territorial Units for Statistics) level 2 in Sweden during 2008.

\begin{tabular}{|c|c|c|c|c|c|c|c|c|c|c|c|}
\hline \multirow[t]{2}{*}{ Source region } & \multicolumn{11}{|c|}{ Destination region } \\
\hline & 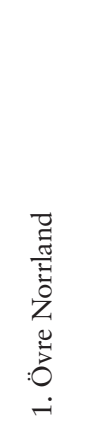 & 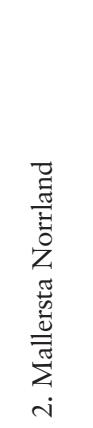 & 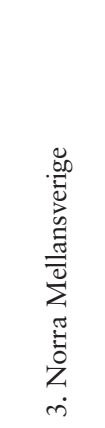 & 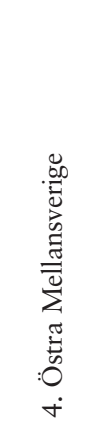 & $\begin{array}{l}\text { E } \\
0 \\
\frac{E}{U} \\
\text { Uू } \\
\dot{0} \\
\text { in }\end{array}$ & 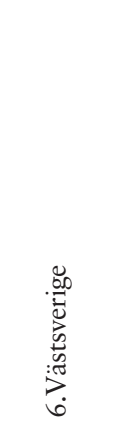 & 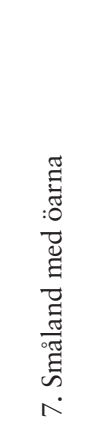 & 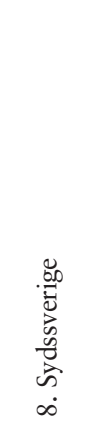 & 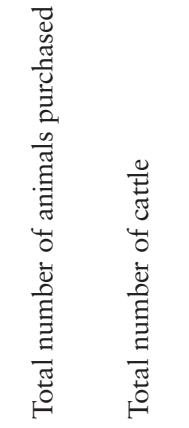 & 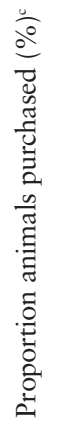 & 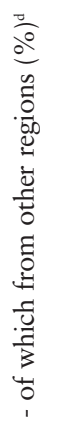 \\
\hline 1. Övre Norrland & 9352 & 118 & 203 & 1568 & 0 & 355 & 0 & 0 & 1159689559 & 12.9 & 19.4 \\
\hline 2. Mallersta Norrland & 679 & 8132 & 1692 & 1397 & 82 & 337 & 165 & 2 & 1248688794 & 14.1 & 34.9 \\
\hline 3. Norra Mellansverige & 60 & 601 & 20143 & 1805 & 102 & 1601 & 431 & 11 & 24754179020 & 13.8 & 18.6 \\
\hline 4. Östra Mellansverige & 289 & 37 & 2286 & 38326 & 855 & 2235 & 5038 & 567 & 49633379297 & 13.1 & 22.8 \\
\hline 5. Stockholm & 44 & 36 & 269 & 1928 & 1445 & 126 & 205 & 45 & 409831103 & 13.2 & 64.7 \\
\hline 6.Västsverige & 72 & 15 & 1174 & 1481 & 50 & 56503 & 2843 & 3271 & 65409496697 & 13.2 & 13.6 \\
\hline 7. Småland med öarna & 51 & 62 & 154 & 3723 & 23 & 3962 & 57104 & 4645 & 69724551724 & 12.6 & 18.1 \\
\hline 8. Sydssverige & 50 & 29 & 58 & 329 & 5 & 1646 & 1791 & 44250 & 48158343088 & 14.0 & 8.1 \\
\hline Total number of animals purchased & 10597 & 9030 & 25979 & 50557 & 2562 & 66765 & 67577 & 52791 & & & \\
\hline Total number of cattle & 89559 & 88794 & 179020 & 379297 & 31103 & 496697 & 551724 & 343088 & & & \\
\hline Proportion animals purchased $(\%)^{a}$ & 11.8 & 10.2 & 14.5 & 13.3 & 8.2 & 13.4 & 12.2 & 15.4 & & & \\
\hline - of which from other regions $(\%)^{b}$ & 11.7 & 9.9 & 22.5 & 24.2 & 43.6 & 15.4 & 15.5 & 16.2 & & & \\
\hline
\end{tabular}

${ }^{a}$ Calculated as: (total number of cattle purchased/total number of cattle) x 100; ${ }^{b}$ Calculated as: (1 - number of cattle purchased within region/total number of cattle) x $100 ;{ }^{\mathrm{c}}$ Calculated as: (total number of cattle soald/total number of cattle) $\mathrm{x} 100$; ${ }^{\mathrm{d}}$ Calculated as: $(1$ - number of cattle sold within region/total number of cattle) $\mathrm{x} 100$. 
(a)

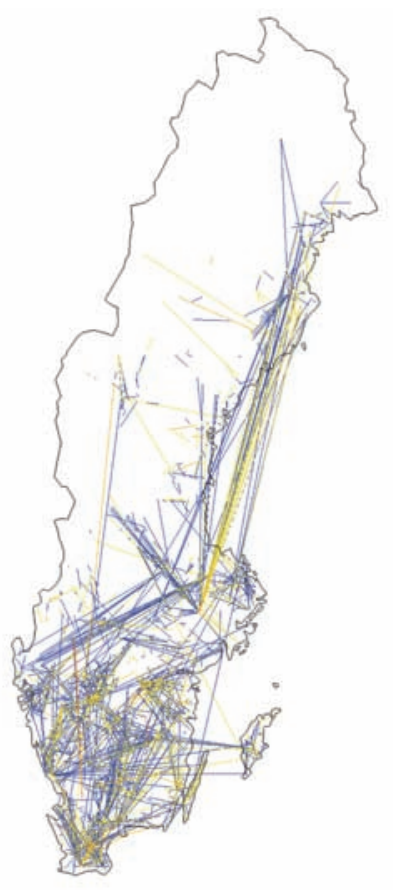

(b)

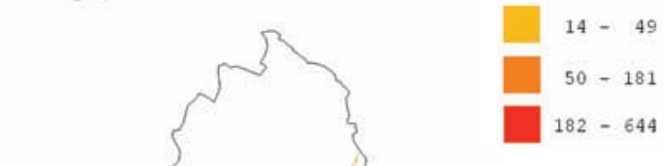

(c)

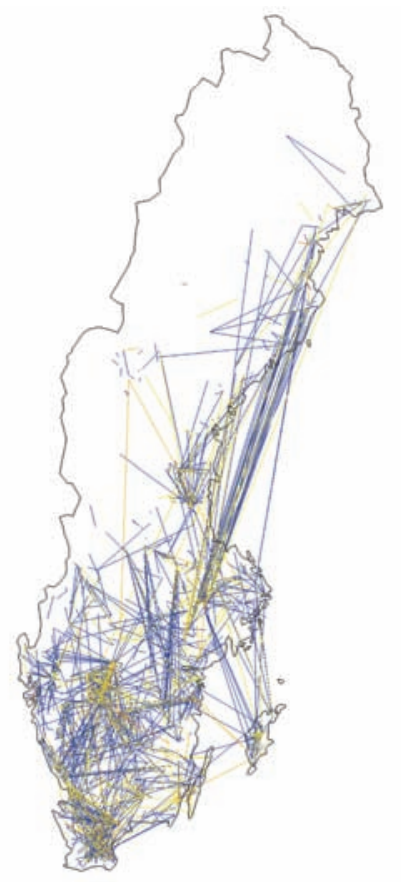

(d)

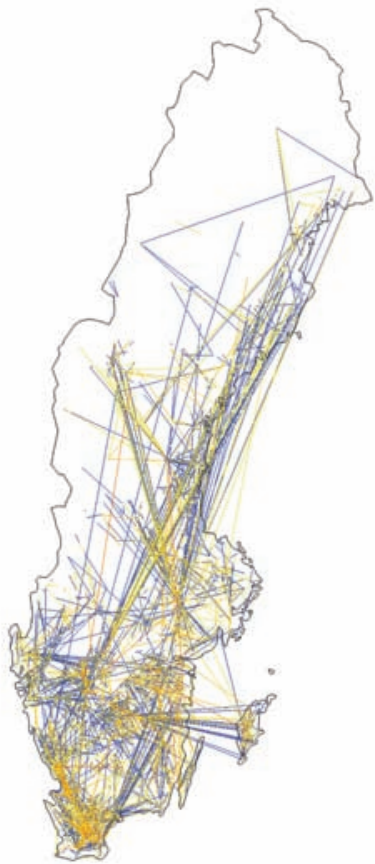

Fig. 5a-d. Spatial extent and intensity of movements of animals between cattle holdings in Sweden during four two-week intervals; (a) 28 December 2007 - 10 January 2008; (b) 4 April - 17 April 2008; (c) 27 June - 10 July 2008; and (d) 3 October 16 October 2008. The different colours represent the algorithm sum of each cell in the grid, i.e. indirectly the sum of movements passing through each cell, where straight lines are chosen to represent each movement between a source and a destination holding. () Lantmäteriet Gävle 2009, permission number I 2009/0830. 
are given with four 2-week intervals in Figs. 5a-d, representing data from winter, spring, summer and autumn in the 2007-2008 period. A complete sequence of maps for the whole study period has been compiled into an animated GIF-file (see the HTLM version of the manuscript). The maps show that several between-herd cattle movements, both short and long distance, take place in Sweden each week. On the whole, the intensity and extent of movements varied slightly over the study period.

Spatial scan statistics based on data from 2008 indicated uneven distributions of cases, i.e. purchased or sold animals, in space and time. The statistics indicated presence of two clusters with more sold animals than expected (Fig. 6a). The primary cluster was located in the middle of Sweden and had more observed cases than expected in October and November. During the same time period, there was an additional, secondary cluster in the south of Sweden. For purchases (Fig. $6 \mathrm{~b})$, there was a primary cluster in the very south of Sweden between 1 September and 30 November and a secondary cluster, in the middle of Sweden between 1 October and 31 December. There was also a secondary cluster in the southeast of Sweden with less purchased animals than expected between 1 June and 31 August. In purely temporal analyses, October and November had significantly more cases of both sold and purchased animals.

\section{Discussion}

The study, based on more than three years of data of actual cattle transfers, shows that there are movements throughout the year and between more or less all Swedish regions where cattle are present. Although, as already reported by Nöremark et al. (2009a), the number of movements over the years showed a fairly strong seasonal variation, the spatial visualisation showed that the geographical extent is more or less intact over the months. In comparison to presenting the transfer numbers in graph format, this map-based technique also emphasised the fact that the lowest level of movement intensity was surprisingly high. From the maps it is clear that the cattle trade is constantly active at quite a high level. Recent studies have concluded that many farms lack sufficient biosecurity routines (Nöremark et al., 2010a), and there is, in other words, a constant risk that contagious diseases can spread in the population. Historically, Sweden has had a relatively low level of infectious diseases in livestock and claim freedom from several serious diseases that are present on the European continent. However, due to increased travel, more open borders within the

Table 3. Results from a spatial scan statistic (Kulldorff, 1997) based on data on the number of purchased and sold individual cattle in Sweden in 2008. The extent of spatio-temporal clusters is presented in Fig. 6a and 6b.

\begin{tabular}{|c|c|c|c|c|c|c|}
\hline & \multirow[t]{2}{*}{ Cluster number ${ }^{\mathrm{a}}$} & \multirow[t]{2}{*}{ Time period } & \multirow[t]{2}{*}{ Postal code areas $(n)$} & \multicolumn{2}{|c|}{ Number of cases } & \multirow[t]{2}{*}{ Relative risk ${ }^{\mathrm{b}}$} \\
\hline & & & & observed & expected & \\
\hline \multicolumn{7}{|l|}{ Cluster in space and time } \\
\hline \multirow[t]{2}{*}{ Solid animals (Fig. 7a) } & 1 & 1 Oct - $30 \mathrm{Nov}$ & 71 & 19,565 & 11,620 & 1.73 \\
\hline & 2 & 1 Oct - $30 \mathrm{Nov}$ & 153 & 19,862 & 11,966 & 1.71 \\
\hline \multirow[t]{3}{*}{ Purchased animals (Fig. 7b) } & 1 & 1 Sep - $30 \mathrm{Nov}$ & 40 & 15,277 & 7,321 & 2.15 \\
\hline & 2 & 1 Oct - 31 Dec & 129 & 27,897 & 17,135 & 1.70 \\
\hline & 3 & 1 Jun - 31 Aug & 49 & 10,551 & 17,232 & 0.60 \\
\hline \multicolumn{7}{|l|}{ Cluster in time } \\
\hline Solid animals & 1 & 1 Oct - 30 Nov & n.a. & 73,121 & 48,085 & 1.70 \\
\hline Purchased animals & 1 & 1 Oct - $30 \mathrm{Nov}$ & n.a. & 72,758 & 47,569 & 1.71 \\
\hline
\end{tabular}

${ }^{\mathrm{a}}$ Cluster number 1 indicating primary cluster and cluster numbers $>1$ indicating secondary clusters; ${ }^{\mathrm{b}} p=0.001$ for all relative risks presented in the table; n.a. = not assessed. 
(a)

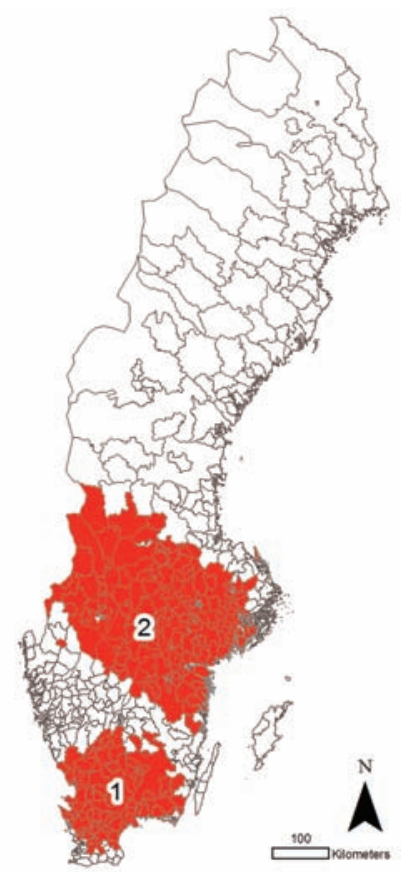

(b)

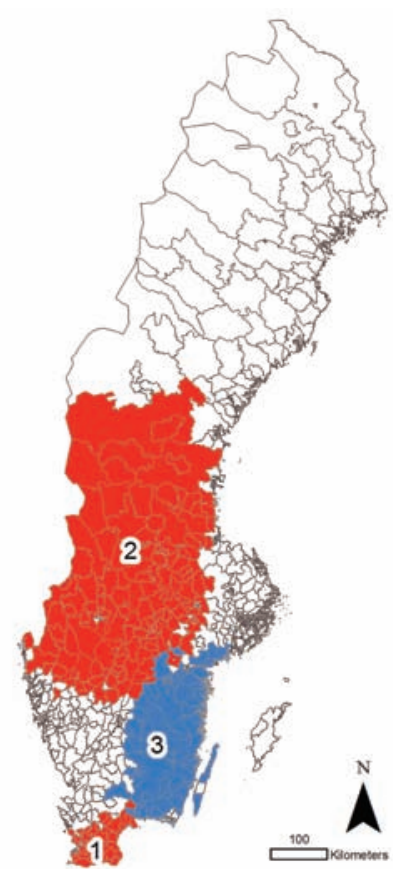

Fig. 6a-b. Postal code areas with significantly higher (red) or lower (blue) relative risks as regards cases of cattle trade by month in Sweden in 2008. The numbered clusters were detected using a spatio-temporal scan statistic with a maximum spatial cluster size of $25 \%$ of the population at risk and a maximum temporal cluster size of $25 \%$ of the study period. Details of each cluster are given in Table 2. Fig. 6a is based on numbers of sold animals, whereas Fig. $6 \mathrm{~b}$ is based on the numbers of purchased animals; both of these in relation to the numbers of non-traded cattle. () Lantmäteriet Gävle 2009, permission number I 2009/0830.

European Union, changes in climate etc., the risk of introduction of previously absent diseases may have increased in recent years. In comparison with other countries, Swedish farmers have been spared from major disease outbreaks and there are indications that this has lowered their awareness regarding this type of threat (Nöremark et al., 2009b, 2010a). With modern communication and transports allowing quick and long distance contacts, the introduction of an exotic and highly contagious disease could therefore have massive consequences.

An outcome of the present study is that there are several long-distance contacts between different parts of Sweden and that a considerable proportion of sold and purchased animals are traded between regions. Instead of simple proportions of traded animals, more complex parameters of trade intensity and probability of contact can be estimated through network analysis (Dubé et al., 2009; Nöremark et al., 2010b). Spatial analyses of herds classified by such network parameters could contribute further to the understanding of the existing flow of animals between herds and the risk of disease spread in this population.

In the present study, dairy cattle and beef cattle were treated as one population. However, in reality there are subpopulations with limited contact, different breeds, slightly different age distribution and so on. Calves born on dairy holdings are often sold to specialised holdings for meat production. Suckler herds, on the hand, may also deliver calves to units for specialised meat production but are expected to have little contacts with dairy herds. This kind of movement patterns needs to be further investigated and should preferably be taken into consideration in the control of infectious diseases and the design of 
risk-based surveillance.

In 2008, an outbreak of BT, which had previously been absent from the country, was detected in the south of Sweden (Sternberg Lewerin et al., 2010). As part of the BT disease control strategy, surveillance and vaccination zones of increasing size have been implemented in the south of Sweden since September 2008 (Anonymous, 2008). Although there are restrictions related to the movement of cattle between the zones, our results indicate that this has not lead to a large decrease in the general numbers of movements. In addition, apparent changes in spatial pattern of registered movements are not seen in the comparison of maps from before and after the outbreak. Movements were allowed under certain conditions that were expected to work as a disincentive. For a complete understanding of such consequences of the restrictions, a more detailed investigation, including comparison of movement data and the exact extent of the specific zones, is required.

One drawback of illustrating events like movements between holdings by connecting the starting point with the endpoint is that very short lines are not as visible as longer lines and seemingly impart more weight to the long-distance movements. Thus, the maps presented here are not optimal for estimating the proportion of short-versus long-distance movements in the country. It can also be difficult to interpret grid colours in areas covered by many movement lines. Depending on the data and the objective, both the scale of the map and the size of the applied time interval can be changed in order to adjust for this. However, when the overview and general pattern constitute the main objective, this is less relevant than in investigations where specific events need to be traced. The time interval chosen (14 days) in this study was nevertheless considered short enough to avoid overlapping of lines and confusing information due to extreme transfer intensity in some areas. It was also long enough to enable a manageable summary of three and a half years of data, i.e. a sequence of 91 maps. It should also be noted that the maps show straight line approximations of movements and that these cannot be used to make conclusions about the actual routes of transports.

The spatial overview given in the maps is, undoubtedly, extremely valuable in disease outbreak situations. However, it is important to keep in mind that tracing of specific contacts cannot solely be based on information from databases such as the cattle movement register used here. Although the register is considered relatively complete, our results show, in agreement with previous findings (Nöremark et al., 2009a), that missing and incorrect reports exist. A varying delay in reporting can also be expected.

The grid network maps from this study were generated through the use of open-source tools and software. Thereby, the cost of GIS software was avoided and sharing of programme code is facilitated. The technique that is described is further based on scripts that comprises all main parts of map creation and also allows for inclusion of iterative processes. This was an important prerequisite due to the large number of maps to be generated and the demands for high reproducibility.

In conclusion, the technique that is described in this paper can be used to generate map sequences that give an overview of the extent and intensity of movements such as between-herd animal movements. With the correct setting, the spatial overview can capture information from large datasets, in this case more than 900,000 events. The way the georeferenced data is visualised is also relatively concrete which enables rather direct interpretation of results. Based on the resulting maps, both general trends and indications of more specific aspect or complicated patterns can be identified and communicated to other researchers, laymen and/or decisions-makers.

\section{Acknowledgements}

The authors wish to thank Dr. Maria Nöremark for sharing her insight in movement database issues. We are also grateful for the valuable comments on the manuscript from her and from Dr. Ann Lindberg and Dr. Susanna Sternberg Lewerin. 
The Swedish Board of Agriculture is acknowledged for providing data on cattle movements and location of holdings.

\section{References}

Anonymous, 2000. Regulation (EC) No $1760 / 2000$ of the European Parliament and of the Council of 17 July 2000 establishing a system for the identification and registration of bovine animals and regarding the labelling of beef and beef products. European Union Official Journal L 204, 1-10. Anonymous, 2003. Council Directive 2003/85/EC of 29 September 2003 on community measures for the control of foot-and-mouth disease. European Union Official Journal L 306, 1-87.

Anonymous, 2007. Commission regulation (EC) no. 1266/2007 of 26 October 2007 on implementing rules for Council Directive 2000/75/EC as regards the control, monitoring, surveillance and restrictions on movements of certain animals of susceptible species in relation to bluetongue. European Union Official Journal L 283, 37-52.

Anonymous, 2008. SJVFS 2008:42, Statens jordbruksverks föreskrifter om åtgärder med anledning av fall av blåtunga, Saknr K 37. Swedish Board of Agriculture, Jönköping, Sweden.

Anonymous, 2009a. SJVFS 2009:79, Föreskrifter om ändring i Statens jordbruksverks föreskrifter (SJVFS 2007:12) om märkning och registrering av nötkreatur, Saknr K 30 . Swedish Board of Agriculture, Jönköping, Sweden.

Anonymous, 2009b. Yearbook of agricultural statistics 2009 including food statistics. Official statistics of Sweden, Statistics Sweden, Stockholm, Sweden.

Bigras-Poulin M, Thompson RA, Chriel M, Mortensen S, Greiner M, 2006. Network analysis of Danish cattle industry trade patterns as an evaluation of risk potential for disease spread. Prev Vet Med 76, 11-39.

Bresenham JE, 1965. Algorithm for computer control of a digital plotter. IBM Systems Journal 4, 25-30.

Dubé C, Ribble C, Kelton D, McNab B, 2009. A review of network analysis terminology and its application to footand-mouth disease modelling and policy development. Transbound Emerg Dis 56, 73-85.

Kulldorff M, 1997. A spatial scan statistic. Communications in Statistics: Theory and Methods 26, 1481-1496.

Lindberg A, Alenius S, 1999. Principles for eradication of bovine viral diarrhoea virus (BVDV) infections in cattle populations. Vet Microbiol 64, 197-222.

Lutz M, 2007. Learning Python, Third Edition, O'Reilly Media, Inc.

Matos Baptista F, Nunes T, 2007. Spatial analysis of cattle movement patterns in Portugal. Vet Ital 43, 611-619.

Neteler M and Mitasova H, 2008. Open Source GIS: A GRASS GIS Approach (Third ed.). New York: Springer, pp 84-85.

Nöremark M, Håkansson N, Lindström T, Wennergren U, Sternberg Lewerin S, 2009a. Spatial and temporal investigations of reported movements, births and deaths of cattle and pigs in Sweden. Acta Vet Scand 51, 37.

Nöremark M, Lindberg A, Vågsholm I, Sternberg Lewerin S, 2009b. Disease awareness, information retrieval and change in biosecurity routines among pig farmers in association with the first PRRS outbreak in Sweden. Prev Vet Med 90, 1-9.

Nöremark M, Frössling J, Sternberg Lewerin S, 2010a. Application of routines that contribute to on-farm biosecurity as reported by Swedish livestock farmers. Transbound Emerg Dis 57, 225-36.

Nöremark M, Håkansson N, Sternberg Lewerin S, Lindberg A, Jonsson A, 2010b. Network analysis of cattle and pig movements in Sweden; measures relevant for disease control and risk based surveillance, submitted.

Robinson SE, Christley RM, 2006. Identifying temporal variation in reported births, deaths and movements of cattle in Britain. BMC Vet Res, 2-11.

Sternberg Lewerin S, Hallgren G, Mieziewska K, Treiberg Berndtsson L, Chirico J, Elvander M, 2010. Infection with bluetongue serotype 8 in Sweden 2008. Vet Rec 167, 165-170. 